\title{
CONTEÚDO DIDÁTICO MULTINÍVEL PARA PERSONALIZAÇÃO REATIVA EM SISTEMAS TUTORES INTELIGENTES
}

\author{
Francisco Ramos de Melo M* $^{\ddagger *}$ \\ chicormeyahoo.com.br \\ Sirlon Diniz de Carvalho* \\ sirlondiniz@yahoo.com.br
}

Gilberto Arantes Carrijo*

gilberto@ufu.br

\author{
Edna Lúcia Flôres* \\ edna@ufu.br
}

\author{
Weber Martins ${ }^{\dagger}$ \\ weberdufg.br
}

\section{Antônio Cláudio Paschoarelli Veiga* \\ acpveiga@ufu.br}

\author{
*Universidade Federal de Uberlândia \\ Faculdade de Engenharia Elétrica \\ Uberlândia- MG - Brasil \\ †Universidade Federal de Goiás \\ Faculdade de Engenharia Elétrica e Computação \\ Goiânia - GO - Brasil \\ ${ }^{\ddagger}$ Universidade Estadual de Goiás \\ UNUCET/UNUEAD- \\ Anápolis- GO - Brasil
}

\section{ABSTRACT}

Multi Level Didatic Content for Reactive Personalization On Intelligent Tutor Systems

This paper presents a model for organization of educational content in connectionists intelligent tutoring systems. The availability of educational content in a single format has emerged as a problem for many students. The inadequacy of a single format of content that ignores differences in individual profiles may have inefficient outcomes in the teachinglearning process. The proposed multilevel structure allows for different combinations of concepts for presentation to the same content. Assuming that the pattern of successful organization of the study by a student can be applied to other students with similar profiles, a system was structured to assist in the task of customization reactive content. The customiza-

Artigo submetido em 06/12/2010 (Id.: 1227)

Revisado em 09/03/2011, 23/06/2011, 06/11/2011, 24/02/2012

Aceito sob recomendação do Editor Associado Prof. Jés de Jesus Fiais Cerqueira tion is provided by a neural network that links the student's profile to a proximal learning pattern. This pattern is combined with expert rules to enable a probabilistic selection so that the system presents the reactivity in the different learning stages. The results of experiments indicate that the approach is effective in providing better use of the content in the personal study and its potential use in Distance Education.

KEYWORDS: Didactics personalized contents, learning proximity patterns, intelligent tutor systems, artificial neural networks, didactic personalization.

\section{RESUMO}

Este trabalho apresenta um modelo para organização de conteúdos didáticos em sistemas tutores inteligentes conexionistas. A disponibilidade de conteúdos didáticos em formato único tem se apresentado como um problema para muitos estudantes. A inadequação de um formato único de conteúdo 
que desconsidera diferenças de perfil individual pode apresentar resultados ineficientes no processo de ensino aprendizagem. A proposta de estruturação multinível de conceitos possibilita diferentes combinações de apresentação para um mesmo conteúdo. Pressupondo que o padrão bem sucedido de organização do estudo por um estudante pode ser aplicado a outros estudantes com perfis semelhantes, um sistema foi estruturado para auxiliar na tarefa de personalização reativa do conteúdo. A personalização é propiciada por uma rede neural que associa o perfil do estudante a um padrão proximal de aprendizagem. Este padrão é combinado com regras de especialistas para possibilitar uma seleção probabilistica para que o sistema apresente a reatividade nos diferentes momentos do processo. Os resultados do experimento indicam que a abordagem é eficiente ao proporcionar melhor aproveitamento do conteúdo no processo individual de estudo e o seu potencial emprego no Ensino a Distância.

PALAVRAS-CHAVE: Conteúdos didáticos personalizados, padrões proximais de aprendizagem, Sistemas tutores inteligentes, redes neurais artificiais, personalização didática.

\section{INTRODUÇÃO}

Desde os primórdios da humanidade adquirir e transmitir o conhecimento têm sido os elementos que diferenciam e impulsionam o desenvolvimento humano. O conhecimento tem sido os elementos que diferenciam e impulsionam o desenvolvimento humano. O conhecimento tem sido o instrumento utilizado para promover e assegurar a sobrevivência da humanidade, a evolução pessoal e social e a soberania das nações. Como decorrência, os processos de aquisição (aprendizagem) e de transmissão (ensino, instrução) do conhecimento têm sido alvo de muitos questionamentos e investigações (Dewey, 1900; Thorndike, 1931).

O modo mais antigo e mais utilizado para transmitir conhecimento ainda é o presencial. Uma das principais características desse modelo é a presença simultânea do agente transmissor (professor) e do agente receptor (estudante). Na modalidade presencial, o processo de transmitir é a interação entre o professor e o estudante, onde o professor conduz o processo conforme sua percepção da reatividade do estudante. (Horton, 2000).

Com a expansão tecnológica e baseados na idéia de que parte do processo ensino-aprendizagem pode dispensar a presença física do professor junto aos estudantes, educadores e psicólogos desenvolveram o campo de investigação e de tecnologia educacional, denominado "Ensino à Distância" (EAD). Uma vantagem oferecida pelo EAD é sua característica assíncrona, onde professor e aluno não precisam compartilhar simultaneamente o mesmo espaço e tempo. Sem as limitações impostas pelo modelo presencial, o EAD tem permitido maior disseminação de conhecimentos, favorecendo a popularização do ensino (Jonassen, 2001; Phelan, 2002).

O sucesso de um processo de transmissão de conhecimento deve considerar a organização e apresentação do conteúdo (Libâneo, 1994). Geralmente, para a elaboração, escolha e aplicação de programas e procedimentos de ensino para classes numerosas, os professores desenvolvem um formato único. Neste formato é pressuposto um determinado perfil de estudante. No modelo presencial o formato único apresenta resultados efetivos devido a interação imediata do professor com o aluno no momento em que ocorrem dificuldades. Pela característica assíncrona do EAD, a ação do professor não acontece no instante em que ocorrem problemas, tais como dúvidas ou erro de interpretação. Desta forma, o estudante em um ambiente de aprendizagem individual pode ser prejudicado pela demora ou falta da ação docente (Horton, 2000; Rosenberg, 2001).

Para transmitir conhecimentos, Skinner (1968) aponta a importância e conceitos da organização da sequência didática. Nestes conceitos observa-se a necessidade de estabelecer padrões para sistematizar o processo. Os conceitos do trabalho de Skinner embasam definições de formatação, fracionamento e apresentação do conteúdo que viabilizam a mediação do conhecimento com o emprego de máquinas.

A necessidade de proporcionar instrução a contingentes populacionais cada vez maiores e mais diversos com custo reduzido levou ao desenvolvimento de novas alternativas instrucionais. A introdução de computadores eletrônicos proporcionou o desenvolvimento de muitas tecnologias para auxiliar nos processos educacionais. A inteligência artificial (IA) é uma das tecnologias computacionais que tem proporcionado soluções de interação na modalidade não presencial. Várias aplicações com IA, como os sistemas tutores inteligentes (STI), foram desenvolvidas buscando formas de estabelecer ligações entre o objeto de aprendizagem e o saber do estudante (Dastbaz, 2006; Duque, 2006).

Normalmente, os STIs são desenvolvidos com técnicas de IA clássica, onde os processos de conhecimento são abstraídos e organizados em regras ou estruturas equivalentes. Nas diferentes técnicas empregadas observa-se um esforço no sentido de desenvolver disponibilidades de estratégias diferenciadas e um mecanismo que possibilite a adaptação necessária (personalização) ao estudante. (Rissoli, 2007, González, 2009; Fontenla, 2010). Um grande esforço no desenvolvimento de um STI é a busca de um mecanismo que possa compensar a falta do professor para interagir (reatividade) com o estudante durante a apresentação do conteúdo. Existe um grande esforço no desenvolvimento de técnicas para personalizar reativamente o conteúdo apresentado (Vicari, 2005; Dastbaz, 2006; Duque, 2006, Jimenez, 2006; Méndez, 2008). A per- 
sonalização reativa do conteúdo proporciona uma apresentação adaptada ao perfil do estudante e reajustes durante a apresentação para proporcionar interação com o estudante.

Uma alternativa no desenvolvimento de STIs emprega técnicas de IA conexionista. Carvalho (2002) desenvolveu um sistema utilizando rede neural artificial (RNA) para validar a personalização e a reatividade do STI conexionista. Nesse sistema, foi inserida uma RNA após cada questionário avaliativo do nível de conceito do conteúdo apresentado. O sistema apresentou bons resultados, mas com um grande número de RNAs especializadas.

Melo (2003) simplificou o sistema de Carvalho (2004) concebendo e implementando um STI híbrido utilizando uma única RNA global e regras de especialistas para decisões do sistema na navegação. Posteriormente, foi demonstrada a capacidade do STI híbrido para apresentar outros conteúdos utilizando a mesma RNA (Quinderé, 2008).

Nos trabalhos de Carvalho (2002), Melo (2003) e Quinderé (2008) não foi observada a apresentação de um formalismo matemático. A formalização matemática de um modelo facilita seu entendimento e possibilita a concepção e o desenvolvimento de novos trabalhos. Trabalhos apresentados em diferentes áreas do conhecimento mostram a capacidade de descrição da formalização matemática (Vargas, 2008; Cereda, 2008; Barajas, 2010).

Este trabalho apresenta um modelo para personalização reativa de conteúdos didáticos. No trabalho é proposta uma maneira de reestruturar e formalizar um conteúdo em diferentes níveis de apresentação do mesmo conceito. A combinação de diferentes níveis conceituais possibilita estabelecer um conteúdo personalizado para cada estudante. Adicionalmente é inserido um formalismo para definição de uma trajetória reativa de apresentação do conteúdo. Este formalismo, empregando o método de diferenças finitas, procura fundamentar o desenvolvimento de trabalhos com sistemas tutores inteligentes conexionistas. Um sistema, com o método proposto, identifica o perfil do estudante e estabelece a relação com um padrão proximal de aprendizagem. A partir desse padrão, regras de especialistas complementam a personalização proporcionando reatividade para os diferentes momentos da apresentação do conteúdo. Os resultados demonstram a aplicabilidade das técnicas.

Este artigo está estruturado da seguinte maneira: as seções 2 a 5 apresentam a fundamentação para o processo de personalização dos conteúdos. O método proposto, a descrição do experimento e os resultados obtidos são mostrados nas seções 6 e 7. Na seção 8 são realizadas as conclusões.

\section{COMPUTADORES NA EDUCAÇÃO}

O uso de computadores eletrônicos na educação teve início nos anos 50, com a introdução dos sistemas tutores. As primeiras aplicações desses sistemas são consideradas como simples "viradores de páginas eletrônicos" devido a sua característica estática na apresentação dos conteúdos. Parcela considerável das aplicações educacionais que vieram a utilizar a tecnologia dos sistemas tutores foi classificada como "Instrução Assistida por Computador" (CAI, expressão traduzida do Inglês: "Computer-Assisted Instruction"). No desenvolvimento da customização do tutorial, técnicas de IA foram introduzidas para criar um STI reativo e adaptativo ao estudante durante o processo de desenvolvimento da tutoria. Sistemas tutores utilizando IA são classificados como STIs ou "Instrução Inteligente Assistida por Computador" (expressão traduzida do Inglês "Intelligent Computer-Assisted Instruction" - ICAI) (Rosenberg, 2001).

Para contextualizar a proposta de Sistemas Tutores Inteligentes (STI) baseados em redes neurais artificiais é importante observar a existência de diversas estruturas de tutoriais. De maneira geral, o tutorial é iniciado por uma introdução e no final é realizada uma atividade avaliativa para medir a retenção de conhecimento sobre o que foi apresentado. Em geral as estruturas apresentadas nos tutorias são estáticas, não reativas e com pouca ou nenhuma possibilidade de personalização. O processo de ensino-aprendizagem é altamente dinâmico e a personalização do processo tem muitos fatores a serem considerados (Horton 2000).

O desenvolvimento de um sistema computacional para auxiliar na organização didática de apresentação do conteúdo proposto pelo professor, respeitando a individualidade do estudante, é justificado pela necessidade de criar mecanismos que possibilitem a democratização do conhecimento. Esta democratização é justamente para promover o processo de inclusão daqueles que, por razões adversas, não têm disponibilidade de acesso a um tutor humano na mediação do processo de internalização de seus conhecimentos. Para tal, deve-se considerar que cada estudante tem um perfil particular de inteligência. O ensino a distância (EAD) tem a missão de atender ao estudante de forma que o aprendizado seja significativo para ele (Tajra 2001).

\section{REDES NEURAIS ARTIFICIAIS}

As redes neurais artificiais (RNA) são estruturas de processamento que imitam a atividade de processamento do cérebro humano. A principal característica de uma RNA é a capacidade de estabelecer uma relação dos dados apresentados em suas entradas e efetuar a classificação em padrões na sua saída (Fausett, 1994; Haykin, 2000; Braga, 2007). 
O cérebro humano é composto de neurônios iterligados, formando uma rede neural. Os neurônios biológicos são células nervosas que podem ser funcionalmente divididas em três seções inter-relacionadas: o corpo da célula, os dendritos e o axônio. Os estimulos são recebidos pelos dentritos e são processados pelo corpo da célula que emite uma saída pelo axônio. A saída de um neurônio é repassada para outro neurônio por meio de uma ligação denominada sinapse. As sinapses funcionam como válvulas, sendo capazes de controlar a transmissão de impulsos entre os neurônios na rede neural. O efeito das sinapses é variável e esta variação implementa a capacidade de adaptação ao neurônio. Para implementação das RNAs foi proposto um modelo de neurônio artificial (nodo) similar, em estrutura e funcionamento, ao neurônio biológico. O nodo possui um ou mais sinais de entrada associada a um peso, um sinal de saída e o corpo do neurônio representado por duas funções (soma e ativação). O peso é um valor que indica o grau de importância da entrada na formação do sinal de saída do neurônio. A entrada de dados ocorre com a apresentação das caracteristicas consideradas na classificação em cada uma das entradas da. Cada entrada é ponderada pelo respectivo peso antes de ser inserido na unidade de processamento. Para realizar o processamento o neurônio efetua uma soma de todas as entradas ponderadas pelos respectivos pesos e submete esta soma a uma função prédefinida, denominada função de ativação. Conforme o tipo da função de ativação, é produzido um sinal na saída que é a classificação do padrão apresentado. Para efetuar a classificação, a rede deve passar por um treinamento (Fausett, 1994; Haykin, 2000; Braga, 2007).

A rede neural perceptron multi-camadas (MLP, do inglês Mult Layer Perceptron) é um modelo que possibilita a identificação e classificação de padrões. A classificação de padrões pela RNA do tipo MLP é possivel após o treinamento supervisionado. Neste paradigma é utilizado um conjunto de exemplos dos padrões a serem classificados. Cada elemento do conjunto é composto de um grupo de caracteristicas (utilizadas como entradas) e o padrão correspondente, que representa a saída esperada. Após a apresentação das características na entrada da RNA, a saída claculada pela rede é comparada com a saída esperada. Caso haja diferença, será relizado um reajuste nos valores dos pesos das conexões. $\mathrm{O}$ reajuste dos pesos é realizado iterativamente até que a rede seja considerada treinada. $\mathrm{O}$ algoritmo backpropagation é o mais difundido para o treinamento de redes tipo MLP. Conforme apresentado na Figura 1, nesta arquitetura os neurônios são organizados em camadas de entrada, intermediária e saída (Fausett, 1994; Haykin, 2000; Braga, 2007).

Após o treinamento a RNA tem a capacidade de identificar novos padrões, diferentes dos padrões utilizados no treinamento, estabelecendo uma nova classificação intermediária

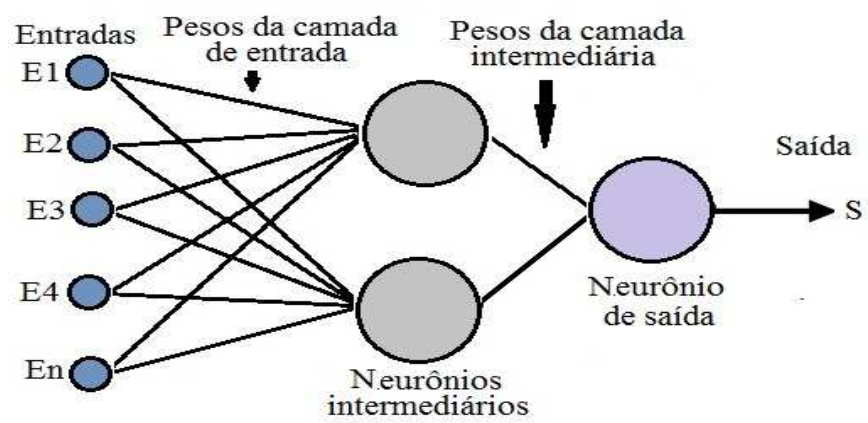

Figura 1: RNA modelo MLP

entre os padrões aprendidos durante o treinamento (Fausett, 1994; Haykin, 2000, Braga, 2007).

Existe uma diversidade de técnicas para reconhecimento e classificação de padrões que se aplicam aos mais variados tipos de problemas (Duda, 2000). A técnica de RNA-MLP aplicada ao problema analisado apresentou boa eficácia, demonstrando ser uma técnica bastante adequada a este tipo de problema (personalização reativa de conteúdos didáticos).

\section{PERFIL DO ESTUDANTE}

$\mathrm{Na}$ análise dos perfis de estudantes pode-se constatar que não existe um modelo único de perfil. Na verdade existe uma grande diversidade de perfis de personalidades com variados padrões de comportamento.

Pesquisas na area da Psicologia possibilitaram o desenvolvimento de ferramentas para classificar padrões da mente humana. Os trabalhos estabelecem a relação de padrões de comportamento com as características obtidas empregando testes psicológicos (Hogan, 2006; Gregory, 2007; Schultz 2008).

Segundo Jung (2008), o tipo psicológico é uma explanação da personalidade humana. Ele observou que o comportamento humano não é algo aleatório, onde as ações são resultados do acaso. Ao invés disso, Jung observou que o comportamento segue padrões desenvolvidos a partir da estrutura da mente humana. Desta forma, Jung desenvolveu uma teoria, representada na Figura 2, sobre os tipos psicológicos tendo por base quatro funções e duas atitudes. Essas funções são sentimento, raciocínio, intuição e sensibilidade. E as atitudes são a extroversão e a introversão. Quando a mente humana está em atividade, ela está realizando uma das duas tarefas: obtendo informações (percebendo) ou organizando e priorizando informações para decidir (julgando) (Daniels 1992, Jung 2008). 


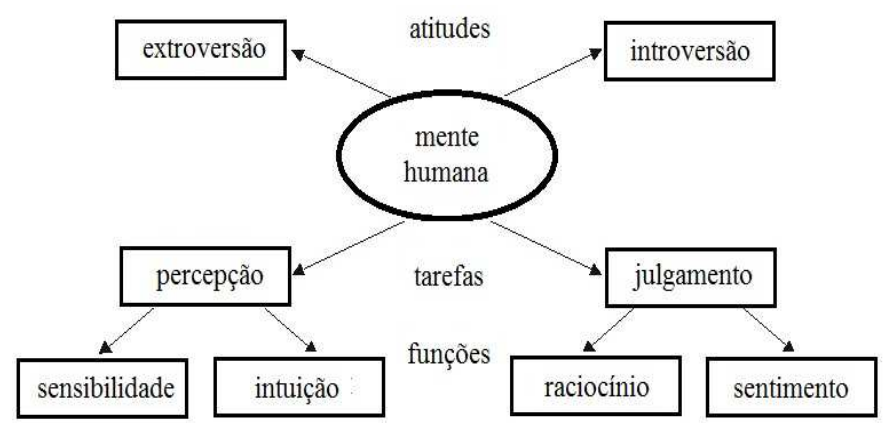

Figura 2: Organização da Mente Humana

A observação da Figura 2 indica que é possivel verificar a possibilidade de estabelecer padrões para classificar as ações mentais.

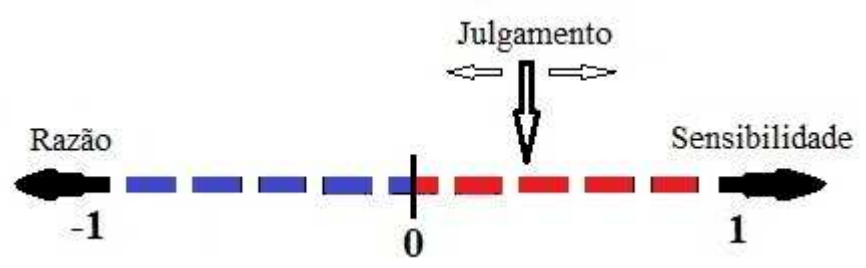

Figura 3: Exemplo de uma dimensão de dicotomia

Os tipos psicológicos são desenvolvidos à medida que as pessoas direcionam sua energia para cada um dos pares opostos (dicotomias). Os testes psicológicos fazem parte do campo de investigação da psicologia que associam itens cotidianos do ser humano a padrões de dimensões que expressam uma característica comportamental (Hogan, 2006; Gregory, 2007). Normalmente, essas dimensões são representadas por dicotomias. Dicotomias são duas características de uma determinada dimensão posicionadas em extremidades contrárias. O conjunto de resposta aos itens do teste psicológico identifica a tendência de cada característica na dimensão considerada. A Figura 3 mostra um exemplo da dimensão "Julgamento". Neste exemplo, a dicotomia é formada pelas características "Sensibilidade" representada pelo valor $1 \mathrm{e}$ "Razão" representada pelo valor -1 . Pode-se verificar nessa figura que a dimensão "Julgamento" tende para o valor 1 , ou seja, a característica "Sensibilidade".

Para identificar o perfil do estudante, o método proposto utiliza a combinação de três padrões de classificação, cada um com uma região de abrangência (Duda, 2000). Esses padrões são: pessoal, habilidades e pré-conhecimento do conteúdo. O padrão pessoal é um conjunto de características obtidas a partir de um teste psicológico. O padrão de préconhecimento está relacionado com o conteúdo a ser apre- sentado e é definido a partir de um teste inicial contendo questões sobre o conteúdo. O padrão de habilidades é definido a partir de um questionário sobre a situação sóciocultural e a familiarização com tecnologias. Cada teste (psicológico, habilidades e pré-teste) é utilizado para definir o padrão na respectiva região de abrangência (Melo, 2006).

A região de abrangência de uma dimensão $\Psi_{d}$ é definida por um conjunto de itens do teste psicológico. O conjunto das $n$ dimensões $d$ consideradas no teste psicológico forma o padrão pessoal $\Psi$ como mostrado na Equação (1).

$$
\Psi=\sum_{d=1}^{n} \Psi_{d}
$$

O padrão de habilidades $H$ é uma avaliação do contexto sociocultural do estudante. A avaliação pode conter itens como idade, sexo, manuseio de tecnologias, etc. Esse padrão complementa o padrão pessoal $\Psi$ com o objetivo de estabelecer elementos mais próximos da realidade do estudante e sua interação com o conteúdo.

O padrão do pré-conhecimento $K$ do conteúdo é um préteste aplicado antes da apresentação do conteúdo. O objetivo desse pré-teste é verificar o grau de conhecimento do estudante sobre o conteúdo a ser apresentado. Para cada conceito do conteúdo é formulada uma questão no pré-teste.

Cada padrão pode ser visualizado como uma região em um plano multidimensional. Neste plano a região de um padrão específico é definida pela combinação dos valores dos elementos considerados na definição do padrão.

Considerando o padrão psicológico $(\Psi)$, cada estudante tem um perfil único. Porém, se for considerado apenas esse parâmetro, a grande variedade de padrões psicológicos resulta em uma grande quantidade de perfis de estudante. Entretanto, conforme a finalidade de utilização, um padrão psicológico pode ser aproximado a outro padrão semelhante. Utilizar outros padrões como complemento do padrão psicológico pode melhorar a abrangência da região do perfil do estudante. Com o crescimento dessa região, aumenta a probabilidade de regiões comuns. Neste sentido, os padrões de habilidades $(H)$ e de pré-conhecimento do conteúdo $(K)$ possibilitam maior abrangência da região de classificação do perfil do estudante. Aumentando a abrangência da região de classificação (Duda, 2000), é possível classificar por aproximação um maior número de perfis de estudante na mesma região.

O perfil do estudante é uma complexa estrutura resultante da interação de diversos padrões, resultando em um padrão diferenciado para cada estudante (Keirsey1998). Neste trabalho, o perfil do estudante $(\Omega)$ é uma região definida pela 
intersecção dos três padrões (pessoal $\Psi$, habilidade $H$ e préconhecimento do conteúdo $K$ ). Neste trabalho, as caracteristicas destes padrões (características psicológicas, situação sócio cultural e familiarização com tecnologias e pré-teste) são as entradas da rede neural artificial, para definir o perfil do estudante A configuração da RNA (estabelecida no treinamento com exemplos) possibilita que ela classifique, estabeleça a intersecção entre os padrões e apresente na saída os valores do padrão de aprendizagem do estudante. Este padrão é o conjunto de valores com o percentual de preferência por cada tipo de nível do conteúdo.

\section{CONTÉUDOS DIDÁTICOS}

O processo de ensino-aprendizagem pode ser representado pela combinação de ações do professor e do estudante, com o objetivo de assimilar conhecimentos. Nessa representação, podem ser visualizados três elementos: o professor, o estudante e o conteúdo a ser ensinado. O estudante é a parte interagente para qual é direcionado todo o esforço do processo, para desenvolver suas habilidades. O professor é o grande agente do processo, responsável pela direção e organização dos meios que proporcionem ao estudante assimilar conhecimentos do conteúdo (Libâneo, 1994).

Idéias são unidades de conhecimento denominadas conceitos. Um conteúdo didático pode ser entendido como um elemento estruturado de tal forma que o conjunto de conceitos formam um todo (Dahlberg, 1978).

A organização do conteúdo não deve ser entendida como algo mecânico, apenas como uma seleção e organização lógica dos conceitos. Libâneo (1994) recomenda que os conteúdos devem incluir elementos da vivência dos estudantes para torná-los mais significativos. O conteúdo selecionado e organizado pelo professor é apresentado no mesmo formato para todos os estudantes.

$\mathrm{Na}$ modalidade presencial de ensino, o professor interage com o estudante durante a apresentação do conteúdo, identifica suas dificuldades e estabelece alternativas para conduzir o aprendizado. Essa interação entre professor e estudante ocorre durante todo o processo de desenvolvimento do conteúdo.

Em modalidades não presenciais a interatividade é um fator complicador. Pela falta da mediação docente, um formato único de conteúdo pode não atender situações individuais de aprendizagem. Durante a apresentação do conteúdo, pode ocorrer um maior espaço de tempo na ação docente para solucionar a dificuldade do estudante. Ações docentes gerais são inviabilizadas pela pluralidade dos estudantes e das variadas situações do ambiente não presencial.
Assman (2007) enfatiza que o aspecto fundamental da educação reside nas vivências personalizadas de aprendizagem. Assim, como elemento essencial no desenvolvimento do processo, o estudante carece do atendimento de sua individualidade. Com isto, justifica-se a concepção de estratégias e instrumentos para a apresentação personalizada do conteúdo para cada estudante.

\subsection{Conteúdo Multinível}

Um conteúdo $C$ convencional qualquer pode ser definido matematicamente pelo conjunto composto de uma sequência de vários $(n)$ conceitos $\left(c_{x}\right)$, como mostrado na Equação (2).

$$
C=\sum_{x=1}^{n} c_{x}
$$

Os conceitos são organizados em uma sequência lógica para conduzir ao conhecimento (Patten, 1986; Libâneo, 1994). A organização dessa sequência pode ser realizada de diferentes modos, desde a organização clássica até organizações customizadas. A apresentação dessa sequência normalmente é precedida por uma introdução seguida de um teste inicial e ao final é apresentado um resumo sobre os conceitos abordados e realizado o teste final (Horton, 2000).

A organização mais comum é a clássica, onde a sequência do conteúdo é desenvolvida e apresentada da mesma forma para qualquer estudante. De acordo com a Equação (2), o tutorial clássico apresentado na Figura 4 pode ser representado pela Equação (3).

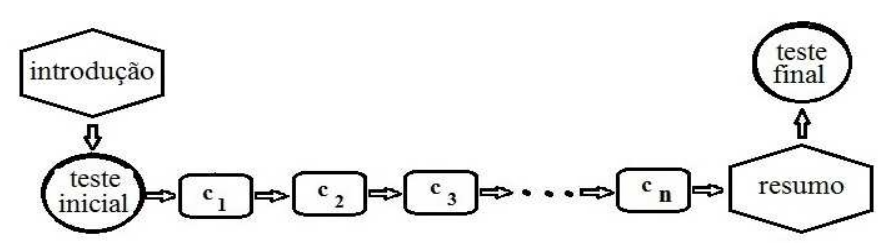

Figura 4: Organização do tutorial clássico

$$
C=\mathbf{c}_{1+} \mathbf{c}_{2}+\mathbf{c}_{3+} \ldots+
$$

A organização customizada é uma forma de personalização do conteúdo porque possibilita a apresentação de partes do conteúdo conforme a necessidade do estudante. De acordo com a Equação (2), o tutorial clássico apresentado na Figura 5 pode ser representado pela Equação (4).

$$
C=c_{2}+c_{5}+c_{7}+\ldots+c_{n}
$$


Um conteúdo personalizado pode ser considerado uma sequência diferenciada de conceitos. Esta diferença está no fato da sequência ser organizada de tal forma que se ajuste o mais próximo possível ao perfil do estudante. A personalização do conteúdo pode oferecer entre outras coisas o melhor aproveitamento do assunto apresentado.

O processo de personalização deve considerar a identificação do perfil do estudante. Para propiciar o melhor aproveitamento do assunto apresentado pode ser estabelecida uma associação desse perfil a um padrão de organização do conteúdo.

Como a concepção do conteúdo convencional é direcionada a um determinado perfil de estudante, normalmente ele é apresentado da mesma forma para qualquer estudante, sem considerar eventuais diferenças. Desta forma, a possibilidade de ajuste do conteúdo para outros perfis de estudantes é quase nula. Assim, é necessário criar uma maneira que possibilite tratar o mesmo conteúdo de formas diferentes.

A sequência do conteúdo didático convencional é inadequada para o processo de personalização. Entretanto, se cada conceito for reescrito com diferentes níveis de apresentação é possível compor o mesmo conteúdo utilizando diferentes combinações desses níveis.

A reestruturação do conceito em diferentes formas de apresentação é denominada neste trabalho de conceito multinível. A estrutura desse conceito é semelhante a mediação docente. Após a apresentação do conceito, o professor procura uma maneira de estabelecer a condução do conhecimento conforme a reação do estudante.

A diferença dos conceitos convencional e multinível é que esse último é mais complexo e requer um esforço adicional para seu desenvolvimento. No conceito multinível, inicialmente deve ser definida a quantidade de níveis de apresentação do conceito e é estabelecido um nível para iniciar a apresentação. A referência para desenvolver os outros níveis é o nível inicial. Em todos os conceitos, níveis idênticos devem ter o mesmo padrão de apresentação.

O conceito multinível $c M$ pode ser definido pela somatória dos vários $m$ níveis $N_{y}$ que compõem esse conceito, conforme mostrado na Equação (5).

$$
c M=\sum_{y=1}^{m} N_{y}
$$

A definição do conteúdo multinível $C M$ pode ser obtida substituindo a expressão da Equação (5) na variável conceito $c$ da Equação (2) como mostrado na Equação (6).

$$
C M=\sum_{x=1}^{n}\left(\sum_{y=1}^{m} N_{y}\right)_{x}
$$

A definição do conteúdo multinível da Equação (6) de acordo com a Equação (5) pode ser simplificada pela Equação (7).

$$
C M=\sum_{x=1}^{n} c M_{x}
$$

As diferentes combinações dos níveis de conceitos do conteúdo multinível possibilita a apresentação personalizada do conteúdo para cada perfil de estudante. Além disto, possibilita criar mecanismos para intervenções mediativas nos diferentes momentos da aprendizagem. Desta forma, é possível que no mesmo conteúdo, cada conceito multinível seja apresentado de forma distinta.

\section{ORGANIZAÇÃO DO SISTEMA}

O objetivo da personalização é proporcionar ao estudante o melhor aproveitamento do assunto apresentado. Após a definição do conteúdo multinível, para prosseguir no processo de personalização, é necessário definir como identificar o perfil do estudante e como organizar o conteúdo de forma mais adequada para esse perfil.

Para personalizar conteúdos didáticos é possível estruturar um sistema considerando o conteúdo multinível $(C M)$, a personalização do conteúdo multinível, o perfil do estudante $(\Omega)$ e o padrão proximal de aprendizagem $\left(L_{\Omega}\right)$. A Figura 6 apresenta a estrutura do sistema proposto.

O sistema proposto é composto de introdução, testes iniciais, sequência de apresentação do assunto e teste final. Na introdução são apresentadas informações gerais sobre o sistema e o assunto a ser apresentado. Após a introdução são realizados os testes de características, habilidades e pré conhecimento. O resultado dos testes são inseridos na entrada da RNA que classifica o perfil do estudante e apresenta na saída o padrão proximal de aprendizagem $\left(L_{\Omega}\right)$. Este padrão fica armazenado na memória do sistema como padrão de referência global para apresentação do conteúdo.

O sistema inicia a sequência de apresentação do conteúdo a partir do primeiro conceito até o ultimo conceito, conforme a definição do conteúdo pelo professor. A apresentação de cada conceito sempre inicia no nível médio. Após a apresentação de todo o conteúdo é realizado um teste final. Este teste efetua a medida de retenção do conteúdo apresentado.

A apresentação do conteúdo é organizada em uma combinação de duas sequencias: geral e localizada. 
A sequencia geral é organizada pelo professor que define a ordem de apresentação dos conceitos. Essa sequência apresenta os conceitos em uma ordem lógica, estruturando o conteúdo desde o primeiro ao último conceito. A sequência geral tem uma estrutura semelhante a organização do tutorial clássico apresentado na Equação (3).

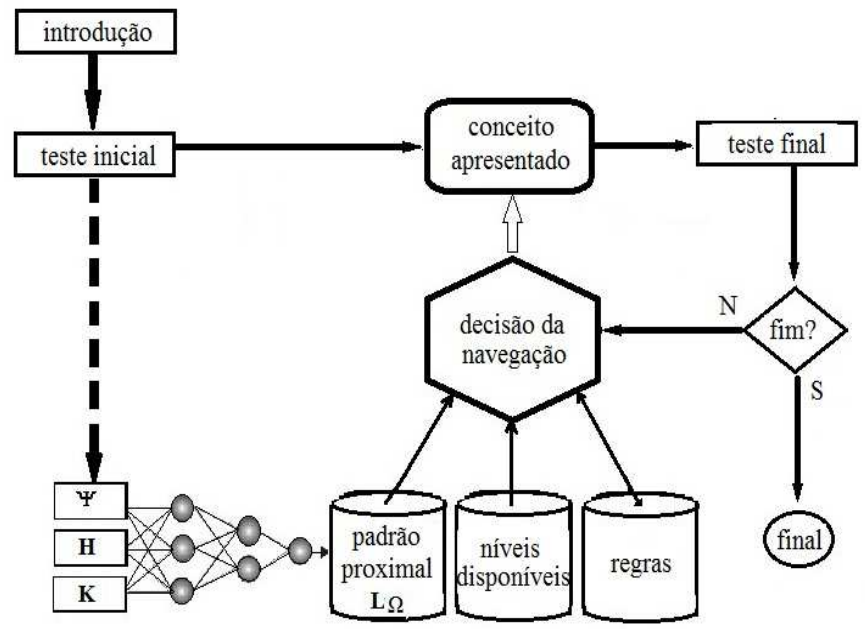

Figura 6: Estrutura do sistema proposto

A sequência localizada é organizada pelo sistema proposto que define quais os níveis serão apresentados e a ordem de apresentação deles de acordo com a sequência geral. Após a apresentação do conceito em um nível qualquer, o estudante pode reagir de diferentes maneiras. Conforme a reatividade, é selecionado um nível para ser apresentado. A sequência localizada corresponde as ações didáticas do professor diante da reatividade do estudante.

No sistema proposto, a organização da sequência localizada inicia sempre no nível médio. Ao final da apresentação de cada nível do conceito, o estudante é submetido a um teste de retenção desse nível. Após avaliar a resposta do estudante, o sistema seleciona a regra local adequada para a situação, no conjunto de regras dos especialistas. Combinando a regra local e o padrão global $\left(L_{\Omega}\right)$, o sistema define o próximo passo na apresentação do conteúdo efetuando um sorteio probabilístico. Este sorteio utiliza a técnica de Monte Carlo (Russel, 2004). O processo de definição do próximo passo é repetido até a conclusão do conteúdo. Desta maneira, o sistema organiza um conteúdo personalizado e reativo ao estudante.

\subsection{Padrão Proximal de Aprendizagem}

No conteúdo multinível $(C M)$ um caminho para a personalização é a definição do quanto o estudante prefere cada um dos níveis desse conteúdo. Para cada um desses níveis do $C M$, a preferência pelo nível $\left(P L_{i}\right)$ é uma função densidade de probabilidade (Agresti, 2009) como mostrado na Equação (8). A probabilidade de cada nível $\left(P L_{i}\right)$ é obtida a partir da probabilidade dos outros níveis.

$$
P L_{i}=1-\sum_{j=1}^{n-1} P L_{j}
$$

A Equação (9) define o padrão de aprendizagem $(L)$ como um vetor de preferência para cada um dos $n$ níveis $\left(P L_{i}\right)$ do conteúdo multinível.

$$
L=\left[P L_{1}, P L_{2}, P L_{3} \ldots, P L_{n}\right]
$$

Com o perfil do estudante $(\Omega)$, e o padrão de aprendizagem $(L)$ definidos é necessário estabelecer uma associação entre eles. Neste trabalho, a proposta de organização personalizada do conteúdo didático consiste em classificar o perfil do estudante $(\Omega)$, e associá-lo com o padrão de aprendizagem $(L)$ da Equação (9).

A partir do perfil do estudante $(\Omega)$ é possível encontrar por aproximação um padrão de aprendizagem $(L)$ que passa a ser o padrão proximal de aprendizagem $\left(\mathrm{L}_{\Omega}\right)$.

O padrão de aprendizagem $(L)$ da Equação (9) é estabelecido a partir da observação de um estudante . O padrão proximal de aprendizagem $\left(L_{\Omega}\right)$ é obtido da mesma forma que o $L$, porém $L_{\Omega}$ é estimado por aproximação considerando o perfil do estudante $(\Omega)$.

Considerando que o padrão de aprendizagem $(L)$ resultou em um melhor aproveitamento para o estudante com perfil $\Omega$, consequentemente poderá auxiliar o aproveitamento por outro estudante, com perfil $\Omega$ semelhante.

Estabelecer a relevância de cada caracteristica e suas relações na definição dos padrões $L$ e $L_{\Omega}$ é uma tarefa complexa para a maioria dos métodos de classificação devido a amplitude do universo de conhecimento envolvido. A solução pode ser o emprego de redes neurais artificiais (Duda, 2000).

Neste trabalho, a RNA deve apresentar um valor que indique a preferência por cada nível do conteúdo multinível conforme a Equação (9). O valor para cada nível varia conforme o perfil do estudante. Desta forma a saída da rede não deve indicar uma classe, mas a contribuição da classe na composição do padrão. Isto é possível de ser obtido por meio do paradigma de aprendizado supervisionado. A RNA do tipo Mult Layer Percerptron (MLP) é utiliza esse paradigma e tem uma caracteristica interessante que é a capacidade de classificar novos padrões, diferentes daqueles utilizados no treinamento (Fausett, 1994; Haykin, 2000; Braga, 2007). Esta classificação é realizada por interpolação (valores intermediários) aos 
padrões aprendidos pela RNA. Esta característica é relevante para o problema deste trabalho.

O método proposto utiliza uma rede neural (MLP) para definir o perfil do estudante $(\Omega)$ e estimar o padrão proximal de aprendizagem $\left(L_{\Omega}\right)$ da Equação (9). A estrutura ilustrada na Figura 6 apresenta a quantidade de camadas, neurõnios e a organização das entradas.

O método proposto utiliza uma rede neural (MLP) para definir o perfil do estudante $(\Omega)$ e estimar o padrão proximal de aprendizagem $\left(L_{\Omega}\right)$ da Equação (9). A estrutura ilustrada na Figura 7 apresenta a quantidade de camadas, neurõnios e a organização das entradas. Conforme pode ser observado nessa figura, foram estabelecidas 17 entradas, subdivididas em tres grupos (conhecimento, habilidades e perfil), para obter as caracteristicas dos padrões que compõem o perfil do estudante.

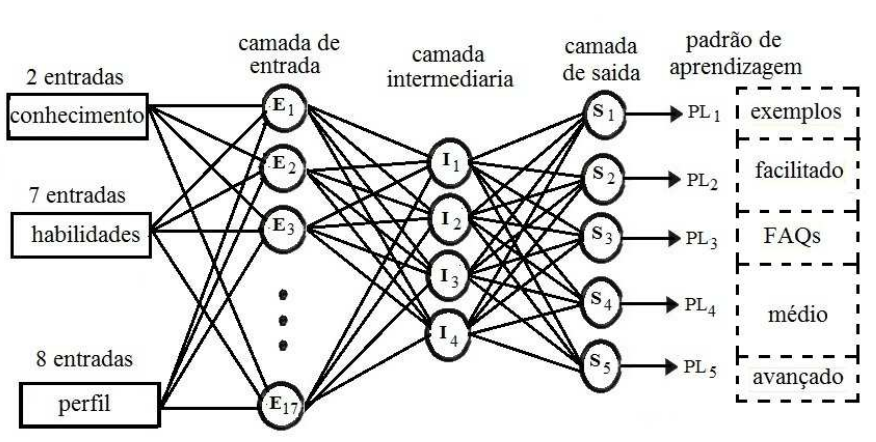

Figura 7: Definição do padrão proximal de aprendizagem

Como um dos objetivos do trabalho é um sistema com o mínimo possível de RNAs, foi definida uma RNA com cinco saídas. O valor de cada saída é a probabilidade de cada nível considerada no sistema. A opção por uma única rede com cinco saídas simplificou a seleção da estrutura, pois a proporção entre as probabilidades foi ajustada de forma automatica pela caracteristica do treinamento supervisionado.

Definidas entradas e saídas da RNA, a próxima etapa é a definição das camadas intermediárias. A seleção da estrutura dessas camadas foi realizada a partir da análise do comportamento de diferentes alternativas na estrutura de organização da rede. Em cada estrutura foi variada a combinação de camadas e a quantidade de neurônios.. A estrutura de rede selecionada, apresentou o menor erro quadrático (Duda, 2000; Agresti, 2007) observado nas curvas de generalização/especialização do treinamento da rede. Desta forma, a estrutura escolhida tem 17 neurônios para a camada de entrada, uma camada intermediária com 4 neurônios e uma camada de saída com 5 neurônios.
O treinamento da RNA foi realizado com dados observados de estudantes com capacidade de organizar a aprendizagem individual. Ao final do treinamento, a RNA ficou capacitada para exercer a função de classificar o estudante em um padrão $\Omega$ e indicar o padrão proximal de aprendizagem $L_{\Omega}$.

\subsection{Definição da Trajetória Didática}

O padrão proximal de aprendizagem $\left(L_{\Omega}\right)$ não é suficiente para definir toda sequência dos níveis para uma apresentação personalizada do conteúdo. Esse padrão é geral e não possibilita a reatividade à apresentação do conteúdo. Além disso, não é possível representar com uma única função toda a sequência do conteúdo personalizado devido a reatividade do estudante nos diferentes momentos de apresentação de cada nível da sequência.

Um dos motivos que o padrão proximal de aprendizagem $\left(L_{\Omega}\right)$ isolado não possibilita a personalização pode ser a forma do seu emprego no sistema. Por exemplo, quando na organização da apresentação for decidido mostrar apenas o nível com maior probabilidade de preferência do estudante, o conteúdo será o mesmo para todos os estudantes com $L_{\Omega}$ maximizado nesse nível. Isso ocorre para o estudante independente do percentual probabilístico do nível maximizado. Esta situação é semelhante a apresentação do conteúdo clássico mostrado na Equação (2), porém no nível maximizado. Esse formato não pode ser considerado uma personalização na apresentação dos conteúdos.

Uma alternativa para tornar o conteúdo multinível $(C M)$ personalizado pode ser o sorteio entre as probabilidades de cada nível. Esta situação pode resultar em um conteúdo diferente para cada estudante, mas pode apresentar incoerências na apresentação. Um exemplo de incoerência é quando o sistema indica leitura do conceito no nível de maior dificuldade quando o estudante errou o teste no nível de menor dificuldade.

A reação do estudante diante da apresentação de um conteúdo pode variar conforme o perfil individual. Diante dessa reação o professor pode modificar a forma de apresentar o assunto. A apresentação personalizada do conteúdo deve ser reativa, além de estar relacionada a um padrão proximal de aprendizagem $\left(L_{\Omega}\right)$. No desenvolvimento de um sistema personalizado, a reatividade deve acontecer nos diferentes momentos da apresentação com o objetivo de corrigir possíveis problemas.

A reatividade não permite representar a sequência da apresentação personalizada em uma única função, como ocorre com a apresentação do conteúdo clássico mostrado na Equação (3). Desta forma, a função que representa a organização do conteúdo, considerando a reatividade pode ser obtida uti- 
lizando derivadas parciais pelo método das diferenças finitas (Griffthis, 2006). Com este método, a correção da trajetória didática pode ser obtida pela derivada do padrão proximal de aprendizagem $\left(L_{\Omega}\right)$ em relação a um padrão que possa ajustar a trajetória didática da apresentação. O resultado dessa derivada possibilita a apresentação de um conteúdo coerente e reativo com o perfil do estudante $(\Omega)$ em cada ponto da apresentação. Este tipo de apresentação do conteúdo pode ser caracterizado como personalizado tanto nos planos global como local.

Alguns pontos devem ser estabelecidos para representar o processo de decisão para a correção da trajetória didática na apresentação personalizada utilizando o conteúdo multinível.

Na navegação em um conteúdo convencional $(C)$, a tendência é que o estudante siga a trajetória didática definida pela sequência estabelecida pelo professor. Essa sequência apresenta apenas um nível de cada conceito. Isto ocorre porque esse conceito é o único nível disponível. A sequência no conteúdo convencional é ilustrada na Figura 8, onde é possível observar que em todos os conceitos a trajetória passa por um único ponto que é o nível $\mathrm{N}_{0}$.

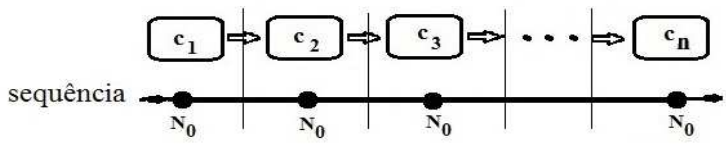

Figura 8: Sequência do conteúdo convencional

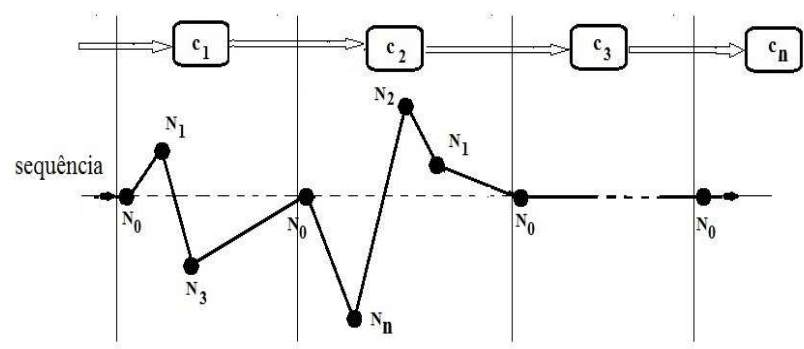

Figura 9: Sequência do conteúdo multinível

No conteúdo multinível $(C M)$ a trajetória didática tende a ser semelhante a trajetória do conteúdo convencional. Porém, conforme a reação do estudante após a apresentação de um nível qualquer, o professor pode efetuar uma variação nessa trajetória. Essa variação considera o padrão proximal de aprendizagem $\left(L_{\Omega}\right)$ e pode conduzir o estudante a outro nível do conceito, conforme pode ser observado na Figura 9.

No sistema proposto o conceito multinível foi estruturado em cinco níveis: três níveis principais e dois auxiliares. Os níveis principais são médio, facilitado e avançado. Os níveis auxiliares são Exemplos e Perguntas e Respostas Frequentes
(FAQs). O nível médio é o nível de referência para os outros níveis e em cada conceito é o primeiro nível a ser apresentado ao estudante. O sistema proposto considera que os níveis principais e auxiliares estão posicionados no plano xy como mostrado na Figura 10.

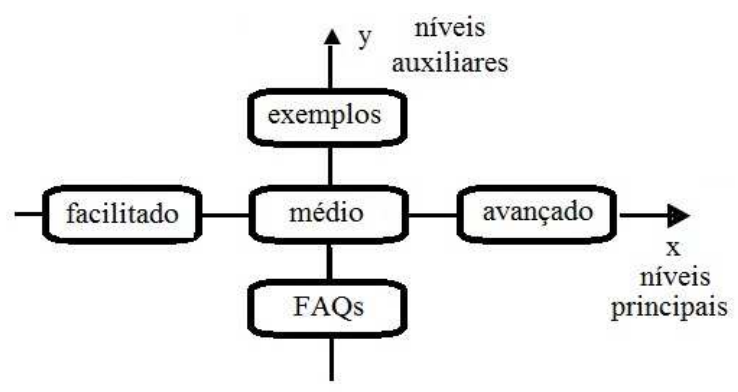

Figura 10: Distribuição do conceito multinível

Considerando na distribuição do conceito multinível (cM) o nível $\mathrm{LP}_{i, j}$ como referência, a formalização matemática para a correção da trajetória didática pode ser estabelecida como mostrado na Figura 11. Caso seja necessário inserir um novo nível no plano de distribuição do conceito multinível $(c M)$, ele será posicionado entre os níveis existentes.

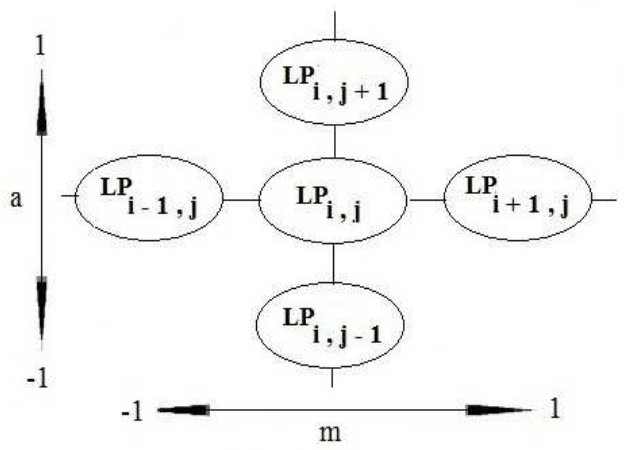

legenda:

$\mathrm{LP}=$ nível

$\mathrm{i}, \mathrm{j}=$ posição de referência

$\mathrm{m}$ = variação no eixo principal

$\mathrm{a}=$ variação no eixo auxiliar

Figura 11: Formalização do conceito multinível

A trajetória didática do estudante tende a seguir a posição $\mathrm{LP}_{i, j}$. Entretanto, conforme a reação do estudante após a apresentação de um determinado nível, o professor pode variar a trajetória na direção de outro nível. O próximo nível a ser apresentado ao estudante é uma região localizada entre o padrão $\left(L_{\Omega}\right)$ desse estudante e a região definida pelo professor para a situação. A correção da variação da trajetória didática pode ser definida como sendo uma correção entre a trajetória do nível de referência e a trajetória do nível para onde o estudante pode ser conduzido conforme sua reatividade.

Para ilustrar a ação de correção da trajetória no plano de distribuição do conceito multinível $(c M)$, pode ser considerada 
a variação no eixo dos níveis principais diante da reação do estudante após a apresentação do nível na posição $\mathrm{LP}_{i, j}$. Se o estudante tiver dificuldade de entendimento, o professor pode apresentar níveis mais fáceis na direção de $L P_{i-1, j}$. Caso contrário, o professor pode apresentar níveis mais avançados na direção de $L P_{i+1, j}$. As variações também podem ocorrer no eixo dos níveis auxiliares.

Para corrigir as situações locais, foi realizado um estudo com especialistas (professores) sobre a atuação deles diante de cada situação possível ao final da apresentação de um conteúdo. Desse estudo foram elaboradas as regras de ação local, denominadas regras de especialistas (Russel, 2004).

A seleção da regra apropriada é realizada apresentando um exercício de múltipla escolha ao final da apresentação de cada nível. Esse exercício é o teste de retenção do nível e é o sensor do sistema para identificar a reação do estudante.

A inserção das regras de especialistas em conjunto com a RNA caracteriza um sistema híbrido. As regras de especialistas no sistema proposto têm a mesma estrutura do padrão proximal (probabilidades para cada nível). Porém, cada regra é especifica para cada situação no teste de retenção realizado após a apresentação do conteúdo.

Para personalizar o conteúdo é necessário o padrão global e o padrão local. O padrão global $\left(L_{\Omega}\right)$ é estabelecido uma única vez antes do inicio da apresentação. O padrão local varia nos diferentes instantes da apresentação. Ao final da apresentação de cada nível conceitual, é possivel verificar a situação local do estudante por meio de um teste, que indica a reatividade. Conforme a reatividade apresentada, o sistema ativa um padrão local (regras de especialistas). A próxima etapa na organização do conteúdo é definir o próximo nível de conceito a ser apresentado.

O ajuste da organização da sequência do conteúdo multinível, pode ser realizado combinando o padrão global (estudante) com o padrão local (professor). No sistema proposto, essa combinação é obtida pelo produto entre as probabilidades dos padrões local e global, como ilustrado na Figura 12. O resultado desse produto é um novo padrão, denominado de padrão de decisão probabilístico. Neste padrão as probabilidades podem ser ampliadas ou atenuadas proporcionalmente a sua representatividade em cada um dos padrões. Neste método é interessante ressaltar que uma atenuação pode até eliminar totalmente a probabilidade de um nível. Esta atenuação pode suprimir incoerências em situações locais. Um exemplo de incoerência ocorre quando após o estudante ter dificuldades no nível facilitado ele vai para um nível mais avançado. Para este exemplo, o estudante pode ter um perfil com preferência pelo nível avançado, mas a regra do especialista (professor) não recomenda este nível, isto é uma possibilidade com valor zero de indicação. A multiplicação de qualquer valor de probabilidade do perfil do estudante pelo valor zero indicado pelo especialista, resulta em zero. Assim, o estudante não será encaminhado para o nível avançado, evitando a incoerência.

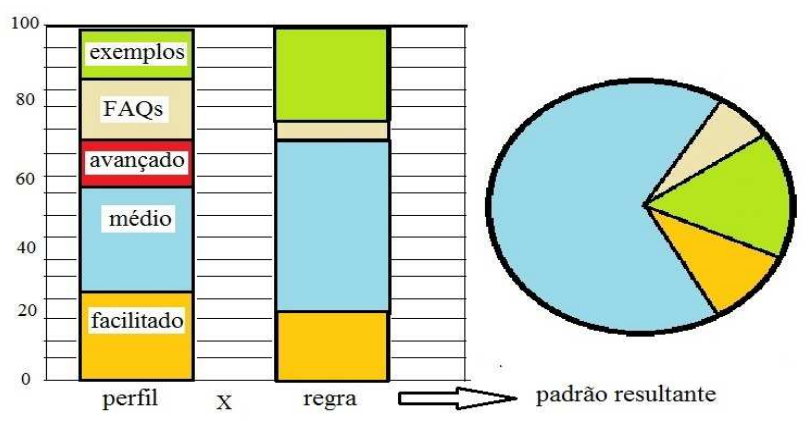

Figura 12: Mecanismo do padrão de decisão probabilística

Cada nível no padrão de decisão probabilístico é representado por probabilidades conforme o perfil do estudante ajustado pelas regras de especialistas de acordo com o desempenho local do estudante no teste de retenção. Com esse padrão, o próximo nível do conteúdo a ser apresentado pode ser obtido utilizando a técnica de Monte Carlo (Russel, 2004). Nesta técnica é realizado um sorteio probabilístico para a escolha de um nível. As maiores probabilidades apresentam maior chance de serem escolhidas, porém as probabilidades menores também podem ser selecionadas.

\section{EXPERIMENTO E RESULTADOS}

Para a realização do experimento foram desenvolvidos três sistemas com interfaces de software semelhantes: sistema de navegação livre, sistema de navegação aleatória e sistema de navegação inteligente. A diferença entre esses sistemas é o mecanismo de decisão para a escolha do nível a ser apresentado na organização do conteúdo. O sistema de navegação inteligente emprega as técnicas de modelagem propostas neste trabalho.

Na navegação livre é o estudante que decide o próximo nível na sequência de apresentação do conteúdo. O objetivo de utilizar essa navegação no experimento é coletar, analisar e selecionar os dados para o treinamento da rede neural do sistema inteligente e também utilizar os dados para a comparação com os dados dos sistemas de navegação aleatória e inteligente. Após essa coleta é realizada a análise do desempenho da navegação de cada estudante. As melhores navegações são selecionadas conforme os critérios estabelecidos por professores participantes do experimento. Alguns dos critérios considerados são: nota, ganho (melhoria), coerência, etc. 
O ganho mede o percentual de melhoria do estudante no intervalo possível entre sua nota inicial e a nota máxima possível no teste. $\mathrm{O}$ calculo considera a relação entre a nota inicial, a nota final e a nota maxima. Assim um estudante com nota inicial 9 terá como intervalo possivel de melhoria apenas 1 ponto. Caso sua nota final for 9,5 terá uma melhoria de 50 por cento sobre o intervalo possível. A Equação (10) mostra o cálculo desse ganho.

$$
\text { Ganho }=\left(\frac{\text { Nota_Final }- \text { Nota_Inicial }}{\text { Nota_Maxima }- \text { Nota_Inicial }}\right) * 100
$$

Neste experimento, os dados utilizados para análise e comparação foram apenas as amostras válidas de cada coleta. Foi considerada amostra válida a coleta onde o estudante conseguiu realizar todos os estágios da navegação em cada sistema.

A coleta de dados do sistema de navegação livre foi a primeira coleta a ser realizada. Nessa coleta participaram estudantes do nível médio e das séries iniciais de cursos superiores. O motivo da seleção desses níveis de estudante foi aumentar a probabilidade de uma amostra com melhor perfil de organização da aprendizagem individual. O número total de amostras válidas nessa coleta foi de 148 estudantes. Dessas 148 amostras, apenas 60 satisfizeram os critérios mínimos estabelecidos. Neste experimento foram estabelecidos os seguintes critérios: nota final maior ou igual a 6, mínimo de $10 \%$ de melhoria e sem incoerências.

No sistema de navegação aleatória a decisão do próximo nível do conceito a ser apresentado é realizada por uma função de sorteio randômico do software. A sequência geral dos conceitos tem a ordem de apresentação conforme definida pelo professor. Entretanto, devido a aleatoriedade do sistema de sorteio do próximo nível, qualquer nível do conceito pode ser apresentado em qualquer ordem. Além da própria aleatoriedade, a sequência de apresentação dos níveis do conteúdo é organizada ao acaso, sem qualquer regra ou lógica. O objetivo da coleta com esse tipo de navegação é comparar com o sistema de navegação inteligente. Com essa comparação, é possível demonstrar que as ações efetivas do sistema inteligente (hipótese alternativa $-\mathrm{H}_{0}$ ) não se devem ao acaso (hipótese nula $-\mathrm{H}_{n}$ ). No sistema de navegação aleatória foram realizadas 31 coletas válidas.

Na navegação inteligente, a decisão do próximo conteúdo a ser apresentado é realizada pelo conjunto de técnicas descritas no sistema proposto neste trabalho. O objetivo é validar a aplicabilidade dessas técnicas na organização personalizada e reativa desses conteúdos. Nessa navegação foram realizadas 31 coletas válidas.
O mecanismo de regras de especialistas foi obtido a partir da coleta de dados com especialistas em docência. Esta coleta foi realizada com 27 professores com experiência no ensino superior em diversas áreas de atuação. Os dados da coleta foram obtidos a partir de um formulário de situações locais. Neste formulário, uma situação local é considerada como sendo cada uma das possibilidades de resposta após o teste de retenção do conteúdo para o nível apresentado. Para cada situação local, o docente apresenta sua ação para apresentar outro nível do conteúdo. Esta ação é um conjunto de probabilidades de indicação para outro nível diante da reatividade do estudante.

Ao final da coleta de dados com especialistas em docência, as regras do sistema proposto foram definidas pela média das indicações dos professores para cada situação local. Desta forma, para cada uma dessas situações foi definida uma regra especifica. Após identificar o padrão da situação local, a regra especifica é disparada por esse sistema indicando as probabilidades de apresentação do conteúdo para cada nível, ou seja, as possibilidades de ação docente.

Os dados selecionados na coleta com navegação livre foram utilizados no treinamento da rede neural. O modelo MLP foi escolhido pela sua capacidade de classificar novos padrões, diferentes dos padrões utilizados no treinamento. Esta classificação é feita por interpolação dos padrões aprendidos pela RNA. A camada de saída foi definida com cinco neurônios, sendo uma saída para cada nível de conceito. A estruturação das camadas de entrada e intermediárias foi definida após a comparação do desempenho final de várias redes, estruturadas de forma distinta tanto em quantidade de neurônios como no número de camadas. A estrutura escolhida foi a que apresentou o menor valor de erro entre o conjunto de treinamento e o conjunto de validação. Após o treinamento, a RNA passou a ser o componente que estabelece o padrão proximal de aprendizagem $\left(L_{\Omega}\right)$ no sistema com navegação inteligente.

Para realizar as coletas no experimento descrito neste trabalho foi desenvolvido um conteúdo multinível com o tema "Introdução a Informática" a ser apresentado de forma textual. A sequência geral deste conteúdo foi organizada em 15 conceitos. Como nesse experimento foi utilizada uma estrutura de 5 níveis, foram desenvolvidos 75 textos, ou seja, 15 conceitos em 5 níveis.

Para analisar o experimento foram realizadas três coletas de dados distintas nos sistemas de navegação livre, aleatória e guiada. Os dados coletados foram analisados em um estudo comparativo das amostras de cada navegação. Este estudo possibilitou comparar características para validar o emprego das técnicas propostas neste trabalho.

Para comparar o desempenho dos três sistemas deste experimento foram observados os resultados de algumas caracte- 
rísticas das navegações. Estas características são: o tempo total para concluir o estudo do conteúdo, a quantidade de níveis utilizados na organização da sequência, a nota final e o ganho. A Tabela 1 mostra o comparativo do desempenho médio das três navegações.

Tabela 1: Comparativo do desempenho médio

\begin{tabular}{ccccc}
\hline \multirow{2}{*}{ Navegação } & \multicolumn{4}{c}{ Médias } \\
\cline { 2 - 5 } & $\begin{array}{c}\text { Tempo } \\
\text { (minutos) }\end{array}$ & $\begin{array}{c}\text { Níveis } \\
\text { visitados }\end{array}$ & Nota final & Ganho \\
\hline Livre & 37,88 & 35,34 & 6,87 & 39,59 \\
\hline Aleatória & 35,97 & 45 & 5,93 & 32,60 \\
\hline Inteligente & 26,80 & 26,71 & 7,21 & 58,02 \\
\hline
\end{tabular}

Pode-se observar na Tabela 1 que a navegação inteligente apresentou melhores resultados em termos de tempo, quantidade de níveis visitados, nota final e ganho em relação as outras duas navegações.Convém ressaltar que a média das notas finais da amostra com navegação inteligente foi maior do que a média da amostra com navegação aleatória. Este fato indica que a sistematização das técnicas empregadas no sistema proposto é responsável pela organização do conteúdo de forma personalizada para proporcionar o melhor aproveitamento do assunto pelo estudante. Tal organização difere da navegação aleatória, onde a sequência de apresentação de cada nível tem sua ordem definida totalmente por acaso.

O padrão global $\left(L_{\Omega}\right)$ definido pela RNA e o padrão local definido pelas regras dos especialistas são os principais elementos na personalização dos conteúdos. O padrão global é definido uma única vez e permanece inalterado até o final da apresentação do conteúdo. O padrão local é variável e é redefinido após cada ponto de controle.

Intuitivamente o padrão local pode ser considerado como principal componente na personalização do conteúdo devido a sua constante interação com a reatividade do estudante. Porém, a finalidade desse padrão é ajustar a apresentação do conteúdo conforme a situação local apresentada. Desta forma, é importante verificar qual é a relevância do padrão global $L_{\Omega}$ no sistema proposto.

Para verificar o comportamento da RNA na definição do padrão global $L_{\Omega}$ e a relevância deste padrão no sistema com navegação inteligente, foi realizado o teste estatístico de correlação de Pearson (Agresti, 2009). O coeficiente de correlação de Pearson mede o grau da correlação entre duas variáveis. As variáveis são similares se o resultado da correlação for positivo e divergentes se for negativo.

No experimento com a navegação inteligente, o cálculo da correlação geral foi feito entre o perfil global $L_{\Omega}$ indicado pela RNA e o perfil observado efetivamente na navegação realizada pelos estudantes. Adicionalmente foi efetuado o cálculo da correlação para cada nível do conteúdo multinível. A Tabela 2 mostra os resultados obtidos das correlações geral e de cada nível. Na Tabela 2 pode ser observado que o valor de 0,875 para a correlação geral indica que a RNA no sistema é muito relevante na definição da sequência didática a ser apresentada ao estudante. Ainda pode ser observado nessa tabela que as correlações mais elevadas ocorreram nos níveis facilitado, avançado e FAQs. As correlações nos níveis Médio e Exemplos foram menores devido as correções impostas pelas regras de especialistas e pela característica do mecanismo do padrão de decisão probabilístico.

Tabela 2: Correlação perfil RNA x Observado

\begin{tabular}{cccccc}
\hline \multirow{2}{*}{ Geral do sistema } & \multicolumn{4}{c}{ Correlação nos níveis } \\
& Médio & Facilitado & Avançado & Exemplo & FAQs \\
\hline 0,875 & 0,694 & 0,952 & 1 & 0,529 & 1 \\
\hline
\end{tabular}

\section{CONCLUSÕES}

Este trabalho apresentou uma proposta de formalização de conteúdo multinível, para possibilitar o desenvolvimento de STIs conexionistas. A automação da apresentação personalizada de conteúdos pode ser ajustada por meio de treinamento com exemplos.

Foram apresentadas as bases formais para representar o processo de interação estudante/conteúdo, ou seja, a trajetória didática de apresentação do conteúdo. A formalização dos elementos que constituem a organização do conteúdo, mostrou-se relevante para representação das técnicas empregadas para identificação do perfil do estudante, associação deste perfil com um padrão proximal de aprendizagem e a estruturação de um conteúdo personalizado e reativo,.

Como o processo de personalização reativa envolve uma interatividade com o estudante, a apresentação do conteúdo varia. Assim, a formalização do conteúdo personalizado não pode ser definida por uma função matemática única. $\mathrm{O}$ emprego de derivadas parciais pelo método das diferenças finitas pode ser empregado para formalizar a reatividade em um conteúdo personalizado.

O trabalho mostrou que a reestruturação do conteúdo em uma estrutura multinivel é um fator favorável ao processo de personalização dos conteúdos. Essa reestruturação favorece a diversificação da apresentação do conteúdo devido as possibilidades de variação na apresentação do mesmo conceito ao estudante.

Para assegurar o processo de personalização do conteúdo, foi verificada a necessidade de estabelecer mecanismos para identificar as características do estudante e associá-las com um padrão de aprendizagem. Essa identificação foi realizada 
utilizando um conjunto de testes de características do estudante. Estas características foram usadas como entrada em uma rede neural que possibilitou a identificação do perfil do estudante e a associação com um padrão proximal de aprendizagem.Os resultados do teste de correlação de Pearson demonstraram que a utilização de redes neurais para estabelecer o padrão proximal foi adequada e um fator bastante relevante na personalização do conteúdo.

A personalização foi complementada com regras de especialistas e a combinação de técnicas probabilisticas, assegurando a reatividade e a intervenção docente nas dificuldades em diferentes momentos da aprendizagem.

Quanto a capacidade de organização da sequência personalizada e reativa do conteúdo didático, os resultados demonstraram que o sistema proposto com navegação inteligente conseguiu realizar essa organização com uma quantidade menor de textos e menor tempo para conclusão do estudo resultando em melhor aproveitamento para o estudante.

A aplicação de padrões proximais de aprendizagem a partir dos padrões de estudantes com boa capacidade de organizar a aprendizagem mostrou ser uma estratégia promissora para auxiliar estudantes que apresentam dificuldades na organização do aprendizagem individual. Desta forma, o emprego do padrão proximal se mostrou eficiente na organização personalizada do conteúdo no sentido de favorecer o estudante em ambientes de aprendizagem não presencial e individual.

Diante do exposto, pode ser entendido que a estruturação do conteúdo multinível, favorece o processo de automatização de uma apresentação reativa e personalizada. Este tipo de apresentação, associado a um padrão proximal de aprendizagem pode ser uma ferramenta favorável para auxíliar estudantes na aprendizagem individual. Desta forma o conjunto das técnicas propostas neste trabalho pode se como elemento facilitador e favorável à inclusão de estudantes em ambientes não presenciais.

\section{REFERÊNCIAS BIBLIOGRÁFICAS}

Agresti, A. e Franklin, C., (2009). Statistics Art and Science of Learning from data. $2^{\text {a }}$ Edition, Pearson.

Alencar, W. S., (2000). Sistemas tutores inteligentes baseados em redes neurais. Dissertação de mestrado em Engenharia Elétrica e de Computação, Escola de Engenharia Elétrica, Universidade Federal de Goiás, Goiânia : GO

Assman, H., (2007). Reencantar a Educação: rumo à sociedade aprendente. Rio de Janeiro, Editora Vozes.
Barajas, F. V., (2010). A formal model for the requirements diagrams of SysML. IEEE Latin-America Transactions, Vol. $8, \mathrm{n}^{\mathrm{0}} 3$.

Braga, A. P.; Carvalho, A. P. L. e Ludermir, T. B., (2007). Redes Neurais Artificiais - Teorias e Aplicações. $2^{\text {a }}$ Ed. Rio de Janeiro, LTC.

Carvalho, S. D. , (2002). Mapas Auto-Organizáveis Aplicados a Sistemas Tutores Inteligentes. Dissertação de Mestrado. Universidade Federal de Goiás. Goiânia, Brasil.

Cereda, P. R. M. e Zorzo, S. D., (2008). Access control model formalism using adaptive automaton. IEEE LatinAmerica Transactions, Vol. 6, $\mathrm{n}^{\mathrm{0}} 5$.

Cruz, C. L.; Patino, H. D. e Carelli, R., (2005). Nuevo algoritmo evolutivo baseado em El modelado matemático de La evolución de una espécie. IEEE Latin-America Transactions, Vol. 3, n 4.

Dahlberg, I., (1978). A referent-oriented, analytical concept theory of Interconcept. International Classification v. 5, n. 3 , p. $122-151$.

Daniels, M., (1992). Self-Discovery the Jungian Way: The Watchword Technique. London \& New York: Routledge

Dastbaz, M.; Mustafa, A. e Stoneham, R., (2006). Issues in Design and Development of Personalised E-Learning Systems. Proceedings of the ED-MEDIA 2006. World Conference on Educational Multimedia, Hypermedia \& Telecomunications. Orlando. USA.

Dewey, J., (1900). Psychology and social practice. Psychological Review.

Duda, R. O.; Hart, P. E. e Stork, D. G., (2000). Pattern Classification. 2nd Edition. Wiley.

Duque, N. J. e Guzman, J. C., (2005). AI Planning for Automatic Generation of Customized Virtual Courses, Frontiers in Artificial Intelligence and Applications. IOS Press, Vol 117. Ámsterdam.

Duque, N. O. e Jiménez, D. J., (2006). Artificial intelligence for automatic generation of Customized courses. Proceedings of the ED-MEDIA 2006-World Conference on Educational Multimedia, Hypermedia \& Telecommunications, USA.

Fausett, L. V., (1994). Fundamentals of neural networks. Prentice Hall. 
Fontenla, J.; Caeiro, M. e Llamas, M., (2010). A SOA Architecture to improve the tailorability and extensibility of e-learning Systems. IEEE Latin-America Transactions, Vol. $8, \mathrm{n}^{\mathrm{o}} 2$.

González, L. A. G. e Ruggiero, W. V., (2009). Collaborative e-learning and learning objects. IEEE Latin-America Transactions, Vol. $7, \mathrm{n}^{\circ} 5$.

Gregory, R. J., (2007). Psychological Testing: History, Principles, and Applications. 5 ${ }^{\text {a }}$ Edition, Pearson.

Griffiths, D. V. e Smith, I. M., (2006). Numerical Methods for Engineers. 2nd edition, London, Chapman and Hall.

Haykin, S. S., (2000). Redes neurais artificiais: princípio e prática. São Paulo, SP : Bookman.

Hogan, T. P., (2006). Introdução a pratica de testes psicológicos Rio de Janeiro, LTC.

Horton, W. K., (2000). Designing Web-based Training. USA.

Jiménez, J., (2006). Un Modelo de Planificación Instruccional usando Razonamiento Basado en Casos en Sistemas MultiAgente para entornos integrados de Sistemas Tutoriales Inteligentes y Ambientes Colaborativos de Aprendizaje Apoyados em Computador. Tesis doctoral. Colombia.

Jung, C. G., (2008). O homem e seus símbolos. Tradução de Pinho, M. L. $2^{\text {a }}$ Ed. Rio de Janeiro, Nova Fronteira.

Keirsey, D., (1998). Please Understand Me II - Temperament, Character, Intelligence, Prometheus Nemesis Book Company, USA.

Libâneo, J. C., (1994). Didática. São Paulo. Editora Cortez.

Lugger, G. F., (2004). Inteligência Artifical: estruturas e estratégias para a solução de problemas complexos. $4^{\mathrm{a}}$ Ed - Porto Alegre, Bookman.

Melo, F.R (2003). Sistemas Tutores Inteligentes Híbridos Baseados em Características Psicológicas. Dissertação de Mestrado. Universidade Federal de Goiás. Goiânia, Brasil.

Melo, F.R. Martins, W. Nalini, L. E. G. Meireles, V (2006). Generalizador Neural de Espaços de Aprendizagem em Sistemas Tutores Inteligentes, XVII Simpósio Brasileiro de Informática na Educação - SBIE. Brasília.

Méndez, N. D. D.; Carranza, D. O., Vicari, R. e Silveira, R. A (2008). Modelo Inteligente Generico para Adaptatividad de Cursos Virtuales. Novas Tecnologias na Educação. V. $6 \mathrm{~N}^{0}$ 1, CINTED-UFRGS
Patten, J.V.; Chao, C.I. e Reigeluth, C.M., (1986). A review of strategies for sequencing and synthesizing instruction. Review of Educational Research, 56(4), pp. 437-471,

Phelan, K. C.; Mendoza-DIAZ, N. V. \& Mathews, S (2002). An example of converting a traditional course into distance learning: an open discussion. Trabalho apresentado na 9th Annual International Distance Education Conference, Austin, Texas, USA.

Quindere, P. S. G.; (2008). Adaptabilidade Temática em Sistemas Tutores Inteligentes Híbridos Dissertação de Mestrado. Universidade Federal de Goiás. Goiânia, Brasil.

Rezende, S. O., (2005). Sistemas Inteligentes - fundamentos e aplicações. Barueri, SP: Manole.

Rissoli, V. R. V., (2007). Uma proposta metodológica de acompanhamento personalizado para aprendizagem significativa apoiada por um assistente virtual de ensino inteligente. Tese de doutorado, Universidade Federal do Rio Grande do Sul, Porto Alegre, Brasil.

Rosenberg, M. J., (2001). E-Learning strategies for delivery knowledge in the digital age. McGraw-Hill, New York, USA.

Russel, S. \& Norvig, P., (2004). Inteligencia Artifcial: tradução da segunda edição. Rio de Janeiro, Elsevier.

Schultz, D. P. e Schultz, S. E., (2008). Teorias da Personalidade, São Paulo, Cengage-Learning.

Skinner, B. F., (1968). The technology of teaching. New York, Appleton-Century-Crofts

Tajra, S. F., (2001). Informática na Educação: novas ferramentas pedagógicas para professores na atualidade. São Paulo. Editora Érica.

Thorndike, E. L., (1931). Human learning. New York, NY : Appleton-Century-Crofts.

Vargas, J. A. R. e Hemerly, E. M., (2008). Observação adaptativa neural com convergência assintótica na presença de parâmetros variantes no tempo e distúrbios. SBA Controle \& Automação, Vol 19, nº 1, São Paulo.

Vicari, R., (2005). Agentes Inteligentes en Educación Virtual. Proceedings of Seminario Internacional. Inteligencia Artificial y Seguridad. Pereira, Colombia. 